\title{
Assessing International Opportunities in Higher Education: \\ A Matrix-based Assessment Tool
}

\author{
Sophie R. Kaufman, David N. Ekstrom, \\ and Lillie M. Shortridge-Baggett \\ Pace University, Lienhard School of Nursing
}

\section{Introd uction}

The pressure on academic institutions to develop sustainable programs is felt both internally and externally. Owing to shrinking operating budgets, universities will only support programs that relate directly to their mission and that are financially viable. External expectations come from funding agencies that typically require institutions to be able to sustain their programs within and often beyond a designated period.

Therefore, we believe that this is the best of times for education abroad professionals to learn some lessons from the business world. Faced with a growing number of international opportunities, the Lienhard School of Nursing at Pace University adapted a business model to assess which opportunities to pursue. Employing a product portfolio matrix approach, the International Opportunities Assessment (IOA) Tool was developed to assess new international ventures using the parameters of Market Attractiveness and Institutional Resources. The tool was piloted on a study abroad nursing course featuring a trip to Iceland. The tool assisted in prioritizing program development for international opportunities.

In the first author's experience as a banker for multinational corporations, she has observed similarities in the international strategies in a wide variety of industries. These strategies invariably incorporate a two-step approach. The first step, whether in publishing, electronics, or pharmaceuticals, is always identifying a well-defined "product" adapted to "customer demand."

What is our product in academia? In our case, Health Care Educational Programs, ranging from continuing education seminars to doctoral programs, including existing programs and those specifically designed as a response to customer demand. What is our customer demand? While our primary customer is the student, we also have to answer to a variety of stakeholders including funding agencies, institutional and individual research partners, and the community 
at large. The specifics of customer demand vary with the institutions involved and with the individual participants' level of education and country of origin. For instance, at the Lienhard School of Nursing (LSN) at Pace University, our customer demand has encompassed Pace students seeking international field study experiences, foreign students looking for exchange programs, universities in search of post-doctoral research supervision, others interested in sending baccalaureate nurses for their master's degree, and yet others who desire a custom-made "train the trainer" continuing education program for their faculty. Spending time to understand the customer demand is most essential. Often, it is during this first stage in exploring an international exchange that cultural differences may become apparent.

The second step in international corporate strategies is to conduct a systematic "market analysis," which allows companies to assess new business ventures using a product portfolio approach and a step-by-step development model. Multinational corporations and global financial institutions tend to approach markets in a very analytical way. Initially, they study opportunities for their industry in a particular market followed by a survey of country risk, which involves political and economic factors including competition, investment requirements and financial return. The latter is typically based on a 5-year business plan that takes into account a number of variables, such as revenue growth, interest rates, currency exchange, and tax rates.

How do not-for-profit organizations, particularly higher education institutions, including those in health care professions, compare with corporations?

- We are "nonprofit" organizations, but our international strategy must be "profitable" in order to be sustainable;

- It is often difficult to secure the initial investment; that is, there is a lack of "seed money;"

- Different tuition structures among international programs create additional funding gaps in student-exchange programs;

- There is a wide variety of licensing requirements in the health care professions around the world.

Given these unique characteristics, is a business model relevant to academic institutions? We believe the answer is yes. One might argue that with our limited resources, a business model is even more appropriate. Using a product portfolio approach is one way to maximize these resources. This premise led to our development of a model assessment tool that can be used for assessing, selecting 
and designing international opportunities. The International Opportunity Assessment (IOA) Tool measures the strategic fit of an international opportunity based on market attractiveness and institutional resources. We will describe the development of this tool and, in order to demonstrate its use, we will provide an example of its application in the assessment of a study abroad course for nursing students at the Lienhard School of Nursing, Pace University.

\section{Literature Review}

Prior to development of the IOA Tool, we conducted a review of the literature to determine the existence of similar methods for assessing international opportunities in academic institutions. References support the value of international experiences for students of various disciplines (Committee on Education and the Workforce, 2000; Cummings, 2001; Koskinen \& Tossavainen, 2004; Schertzer, Schuster \& Zimmerman, 1993; Tabi \& Mukherjee, 2003). Although there is validation of the need for careful planning of international activities within the existing university structure (Iammarino \& O'Rourke, 1999), the challenge of balancing internationalization efforts with other pressures facing universities (Altbach \& Teichler, 2001), and the importance of matching international initiatives to the institution's strategic plan (McBurnie, 2000; Richard, 1997), no systematic procedure or tool for assessing international opportunities is found in the literature.

\section{B a c k g r o u n d}

Similar to many institutions, the Lienhard School of Nursing (LSN) at Pace University is presented with numerous opportunities for the development of international programs. Given the international thrust of the University Strategic Plan and the ambitious international agenda of LSN (Shortridge-Baggett, Ekstrom, \& Kaufman, 2003), the School had a tendency to feel obligated to pursue every single international opportunity. Quickly, and in spite of a growing infrastructure dedicated to international affairs, the need for a more selective approach became evident. Indeed, simply conducting the due diligence (i.e., checking the background of institutions and individuals involved) to decide whether or not to pursue a specific opportunity can consume valuable resources. Hence we had the idea of developing an assessment tool to screen international opportunities in a manner similar to businesses evaluating a new or existing product given their product portfolio strategy.

One way to maximize our limited resources is to use a product portfolio approach. The concept of product portfolio matrix was originally developed in 
the 1970's by a management consulting firm, the Boston Consulting Group (BCG), which suggested that businesses be managed as a portfolio in the way that financial investments are managed. The BCG Matrix classified a corporation's business units according to market growth and market share. The General Electric Company (GE) developed with the consulting firm McKinsey \& Company a more flexible, multidimensional matrix, the GE Business Screen, to expand on the original portfolio approach using two factors: business strength and industry attractiveness (Shewer and Hiam, 1998, pp. 37-45).

Adapting the concept of product portfolio matrix to academic institutions in health care professions, we proposed to use two sets of parameters to assess new international ventures: Market Attractiveness and Institutional Resources (Kaufman, 2003). Market attractiveness can be defined by the institution's prior relationships with this market, the level of education in the health care professions in the countries involved, the appropriate language proficiency, and the immigration factor. The "immigration factor" rating will help the institution to focus on opportunities that do not require visas or countries for which visas are relatively easy to obtain. The institutional resources include the institution's ability to develop and sell the "product" being considered, the interest and availability of faculty, students, staff and alumni to participate in the new venture, financial resources, dedicated infrastructure, and strategic fit with the vision and mission of the institution.

As illustrated here, we can use this product portfolio matrix to decide which international services to maintain and which new opportunities

\section{Figure 1. Product Portfolio Matrix}

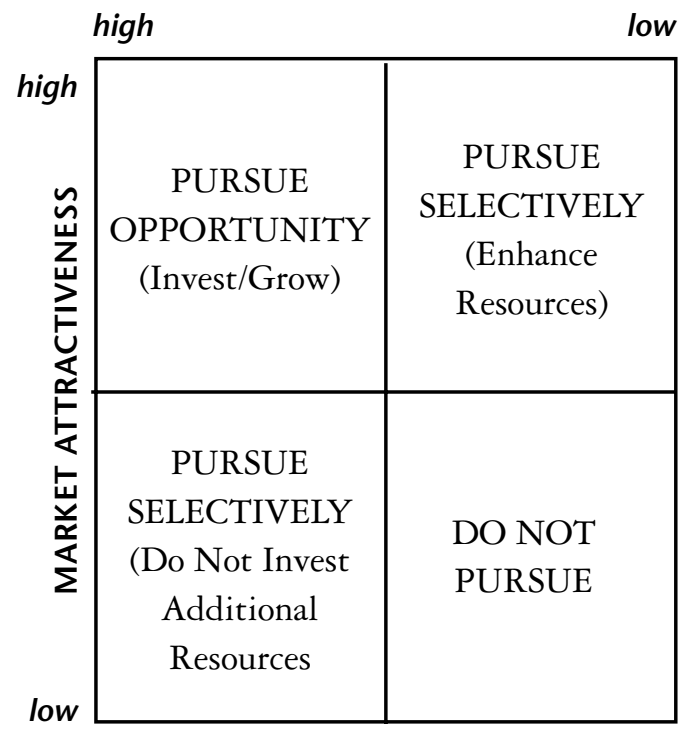
to pursue. The focus should be on services that combine a high level of market attractiveness with a high level of institution's resources (Figure 1, upper left box). Services for which the institution has a high level of resources, yet represent a low level of market attractiveness (Figure 1, lower left box) should be maintained only if they do 
not require additional resources. Often in this category (Figure 1 - lower left box) are "older" programs. The challenge is to convert them into "cash cows," to use marketing terminology, so that they can provide seed funding for those programs which represent a high level of market attractiveness but a low level of institutional resources (Figure 1, upper right box). Opportunities that combine low market attractiveness with low institutional resources should not be pursued. This will ensure that the institution's limited resources are spent to attain its strategic goals.

\section{Description of the IOA Tool}

In an attempt to minimize the time needed to screen international opportunities, we decided to use a two-step process, with a preliminary questionnaire followed by an in-depth questionnaire. We also developed a summary checklist to track progress through the assessment process. These three documents comprise the IOA Tool. The checklist gives a brief summary of the opportunity, identifies the participants, timetable, and next steps (see Appendix A). The first questionnaire consists of four questions assessing strategic fit with the institution's overall goals, interest and availability from LSN participants (faculty, students, staff and alumni), and self-sufficiency (see Appendix B). The reader is prompted to answer using a one to five scale. Opportunities that receive a score below 3 for the Strategic Fit question or a total score below 12 (out of a possible 20) should not be pursued at this time. If some of the questions are not answered, further information will be required. Opportunities that receive a score of 12 or above should be further assessed using the second tool, which provides a more in-depth assessment of the opportunity under consideration.

The second questionnaire consists of six questions assessing Market Attractiveness, and thirteen questions addressing Institutional Resources (see Appendix C). In order to assess Market Attractiveness, the reader is prompted to answer questions about travel requirements of participants, that is, to the US, abroad, or both ways; existence of a prior relationship at the school or University level; level of nursing education and practice in the partner country; language proficiency of the participants given the opportunity; and immigration factors. The section on Institutional Resources attempts to rate the ability of the School and the University to sell the product/opportunity under consideration; the interest and availability of faculty, staff, students and alumni to participate in this opportunity; and the financial resources needed from the institution and from the participants. This section also attempts to quantify the human resources involved in developing the opportunity under consideration and the 
use of dedicated space (e.g., classroom, office, and housing). Responses in each section are assigned values according to an "answer key," with a possible point value of 5 for each item. For each unanswered question, 5 points are subtracted from the total possible score of 75 . International opportunities receiving $75 \%$ of the possible score are considered appropriate for further pursuit by LSN.

In summary, this approach is adapted from what multinational corporations and global financial institutions have been using for decades in a wide variety of industries. Once they have identified a well-defined product adapted to customer demand, they will conduct a systematic market analysis, which allows them to assess new and existing business ventures using a portfolio approach and a step-by-step development model. The IOA Tool is essentially an adaptation of the market analysis and portfolio management approach.

\section{Piloting the IOA Tool}

We decided to test our assessment tool with an international field study course for both graduate and undergraduate nursing students traveling to Iceland. This nursing elective, "Cross-Cultural Study and Comparative Analysis of Health Care Delivery Systems: Iceland," has been offered annually since 2000 (Ekstrom, Sigurdsson \& Gordon, 2001). The major aim of this course is to allow participants to compare and contrast systems of nursing and health care in the USA and a host country, within a framework of primary health care. There are five preparatory seminars followed by a ten-day international field study experience. Iceland was chosen because of an ongoing relationship with the University of Iceland and because it offers an excellent example of a health care system built around the principles of Primary Health Care. During the travel portion of the course, students participate in cultural events in the host country and observe health care through visits to areas such as primary health care centers, geriatric and acute care hospitals, rehabilitation centers, and a dermatology clinic. For the past three years, a highlight of the trip has been a "one-on-one lived experience" for each participant working with an Icelandic nurse.

This course has facilitated interaction among teaching, research, and service (Kahn, et al., 2005). Faculty members draw on insights gained from the experience in teaching other graduate and undergraduate courses. Similarly, students who have participated often refer to experiences gained abroad in their discussions in other courses. They often comment that the experience has given them a new perspective on the US health care system and, as evolving nursing practitioners and leaders, ideas for changing the system. LSN faculty members have consulted 
with Icelandic faculty on various curriculum issues, and one LSN faculty member taught physical assessment in a newly-developed clinical specialty diploma program in Iceland. Ongoing data collection via post-trip surveys and journals has promoted faculty scholarship through presentations at international conferences and the development of manuscripts for publication.

As we considered continuing to offer the Study Abroad Course to Iceland in the spring of 2005, we pilot tested this opportunity with the IOA Tool. Assessment with the IOA Tool I resulted in a total score of 16 out of a possible 20. The first question, assessing strategic fit, received a score of 5 , since the Study Abroad Course to Iceland has been specifically identified as one of the international strategies in the LSN Strategic Plan. The second question, on participants' interest, received a score of 4 , and was explained by the fact that faculty are identified and interested but effective recruitment efforts will be needed to enroll a sufficient number of students. The third question, on participants' availability, received a score of 4 as faculty members have been identified and available but the availability of other participants (students, staff, alumni) is not certain. The fourth and final question of IOA Tool I, on self-sufficiency, received a score of 3 , reflecting the fact that a balanced budget has been prepared, but substantial profits were not expected.

Given the results of IOA Tool I (score of 5 for strategic fit and total score of 16), we proceeded to IOA Tool II. The questions on market attractiveness received the maximum score except for the two questions related to travel requirements (MA1) and immigration factor (MA6), which both received a score of 3 since the opportunity requires Pace faculty/staff/students/alumni to go abroad for a 10-day visit to Iceland. Questions assessing Institutional Resources also received high scores with the exception of participants' financial resources needed (3) and dedicated infrastructure (3). These scores were justified by the fact that the cost of the trip can represent a financial barrier to some students and scholarship assistance, while available, is limited. In terms of infrastructure, it is estimated that 100 to 150 hours of staff time will be needed to pursue this opportunity. The total score for IOA Tool II was 64 out of 75 , or $85 \%$. The Study Abroad Course for nursing students traveling to Iceland passed the test, and based on this result, we decided to continue offering this course.

\section{Conclusion and Recommendations}

Most academic institutions are approached with a variety of international opportunities that do not necessarily fit their mission and strategic plan. Conducting the due diligence on these opportunities can be costly in time and 
Sophie R. Kaufman, DavidN. Ekstrom,

and Liliae M. Shortridge-Baggett

personnel resources. The International Opportunity Assessment Tool presented in this article allows the user to assess quickly whether resources should be spent on pursuing a specific opportunity.

Now that the tool has been tested by the authors, we would like to see a more systematic use of the tool within the Lienhard School of Nursing and throughout Pace University to maximize the impact of the international activities that the University chooses to undertake. We anticipate that faculty, staff and administrators at other institutions will find it useful and adapt it to their particular circumstances. 


\section{$R$ e f e r e n c e s}

Altbach, P., \& Teichler, U. (2001). Internationalization and exchanges in a globalized university. Journal of Studies in International Education, 5, $5-16$.

Committee on Education and the Workforce. (2000). Safety in study abroad programs (US Congress, House of Representatives, Serial No. 106-132). Washington, DC: US Government Printing Office.

Cummings, W. (2001). Current challenges of international education. ERIC Digest. Retrieved January 26, 2005, from http://web23.epnet.com/DeliveryPrintSave.asp? tb=1\&_ug =sid +227CD83C-1934-4F92-9A...

Ekstrom, D., Sigurdsson, H. O., \& Gordon, S. (2001, June). Americans abroad: Decription and evaluation of a nursing study tour to Sweden and Iceland. Paper presented at the ICN 22nd Quadrennial Congress, Copenhagen, Denmark.

Iammarino, N., \& O’Rourke, T. (1999). Planning and implementing an international travel/study course experience for health professionals and students. Journal of Health Education, 30, 166-172.

Kahn, B. L., Kaufman, S. R., Lee, J., Julian, G., Sama, L., Ekstrom, D. N., \& Shortridge-Baggett, L. M. (2005, February). Connecting international teaching, research, and service at Pace University. Paper presented at the American Council on Education Internationalization Collaborative Annual Meeting 2005, Washington D.C.

Kaufman, S. R. (2003, October). How to develop a sustainable international strategy in health care professions education: Lessons learned from the business world. Paper presented at the Tenth Annual Conference of the North American Consortium of Nursing and Allied Health (NACNAH) for International Cooperation, Toronto, Canada.

Koskinen, L., \& Tossavainen, K. (2004). Study abroad as a process of learning intercultural competence in nursing. International Journal of Nursing Practice, 10, 111-120.

McBurnie, G. (2000). Pursuing internationalization as a means to advance the academic mission of the university: An Australian case study. Higher Education in Europe, 25, 63-73.

Richard, O. (1997). Cross-national human resource diversity as value added: The contingent role of international strategy. The Mid-Atlantic Journal of Business, 33, 93-100.

Schertzer, C., Schuster, C., \& Zimmerman, R. (1993, April). Experiential learning from executive MBA study tours overseas: The Xavier University experience-Europe and Asia, 1992. Paper presented at the Twelfth 
Sophie R. Kaufman, DavidN. Ekstrom,

and Lillie M. Shortridge-Baggett

Annual Eastern Michigan University Conference on Language and Communication for World Business and the Professions, Ypsilanti, MI. Schewe, C., \& Hiam, A. (1998). The portable MBA in marketing (2nd Ed.). New York: J. Wiley.

Shortridge-Baggett, L. M., Ekstrom, D. N., and Kaufman, S. R. (2003), International Affairs Strategic Plan. New York: Center for Nursing Research, Clinical Practice, and International Affairs, Lienhard School of Nursing, Pace University.

Tabi, M. M., \& Mukherjee, S. (2003). Nursing in a global community: A study abroad program. Journal of Transcultural Nursing, 14, 134-138.

\section{Ack now I edge ments}

We would like to thank Dr. Beverly L. Kahn, Dr. Harriet R. Feldman, Kraig W. Walkup and the CNRCPIA Executive Team for their review of and input on the development of the IOA Tool. 


\section{Appendix A}

PACE UNIVERSITY, Lienhard School of Nursing

Center for Nursing Research, Clinical Practice and International Affairs

\section{INTERNATIONAL OPPORTUNITY ASSESSMENT (IOA) TOOL CHECKLIST}

Name-Title/Department:/E-Mail/Phone:

Opportunity Title:

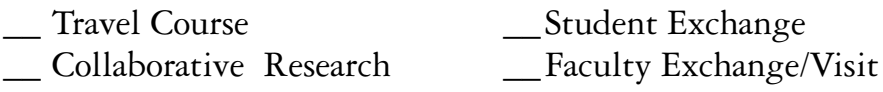

_Fulbright / Other Scholarships __Other

Brief Description of Opportunity (Including Countries Involved):

Participants: This opportunity is primarily designed for:

_ Students _ Faculty _ Staff __Alumni _ Others

But could be developed for:

_Students _Eaculty __ Staff __Alumni __ Others

Timetable: Describe when the opportunity would take place and for what duration:

\section{For Evaluator Use Only:}

Total Score IOA Tool I: (Maximum: 20)

\begin{tabular}{|l|l|}
\hline Proceed to IOA Tool II & \\
\hline Further Information/Discussion Needed & \\
\hline Do not Pursue at this Time & \\
\hline
\end{tabular}

Total Score IOA Tool II: (Maximum:

Next Step(s) and Timeline: 
Sophie R. Kaufman, David N. Ekstrom, and Lillie M. Shortridge-Baggett

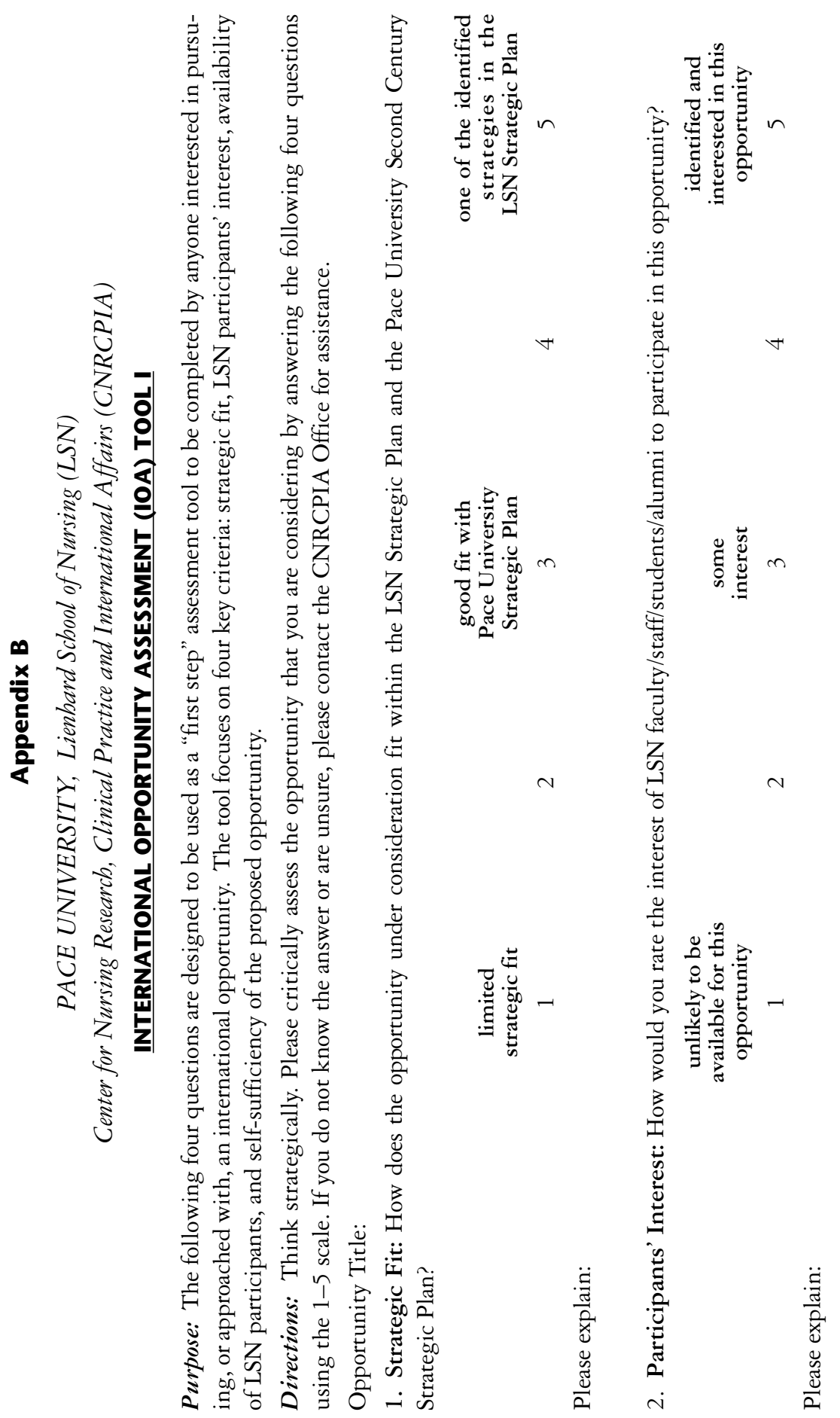


Frontiers: The Interdisciplinary Journal of Study Abroad
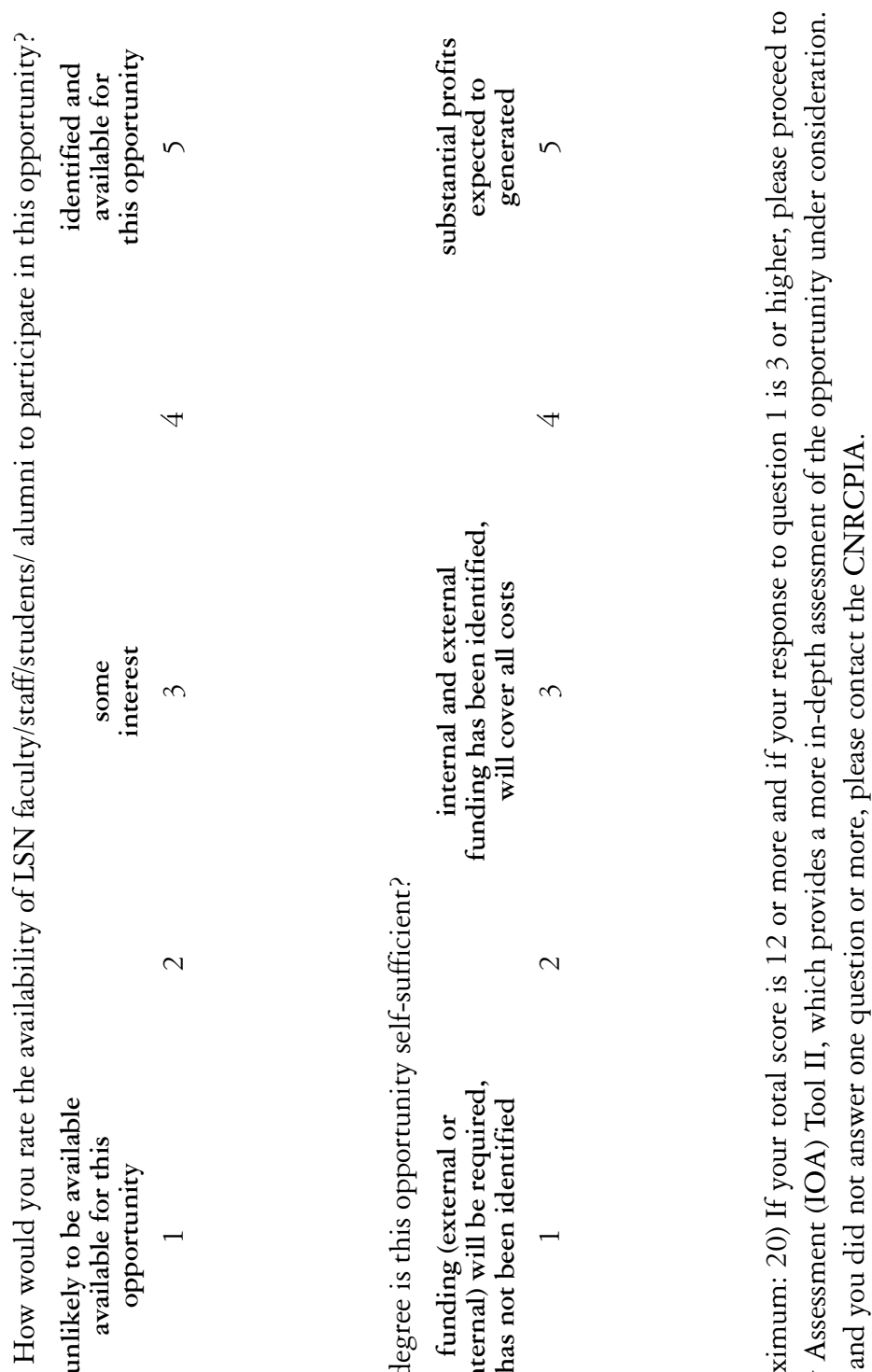

ڤ્仓

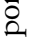

की

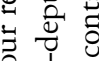

吾

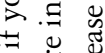

¿

范

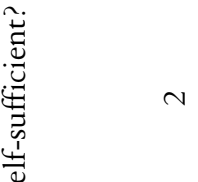

西

ป ڤี

$\therefore$ 들

글

它 $=$

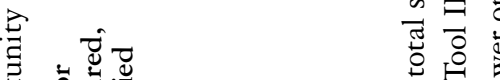

ঊ

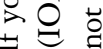

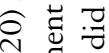

$\ddot{\varepsilon}$ हี శ

$\exists$ :
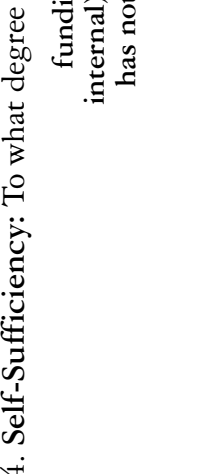

$\dot{m} \quad \dot{2}$

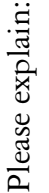

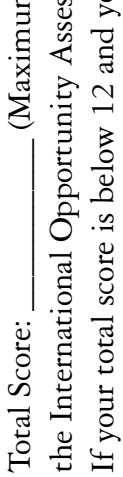


Sophie R. Kaufman, David N. Ekstrom, and Lillie M. Shortridge-Bagget t

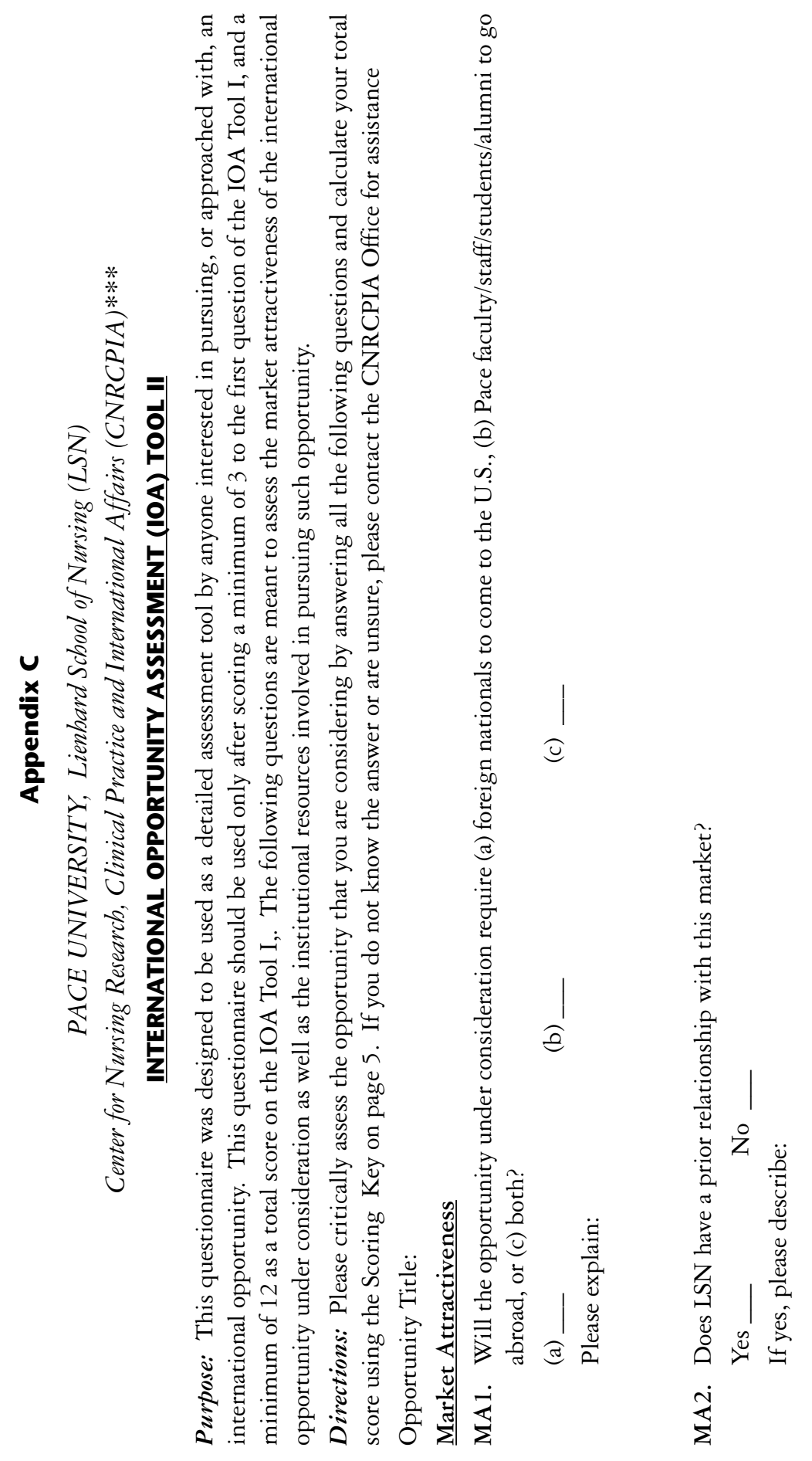


Frontiers: The Interdisciplinary Journal of Study Abroad

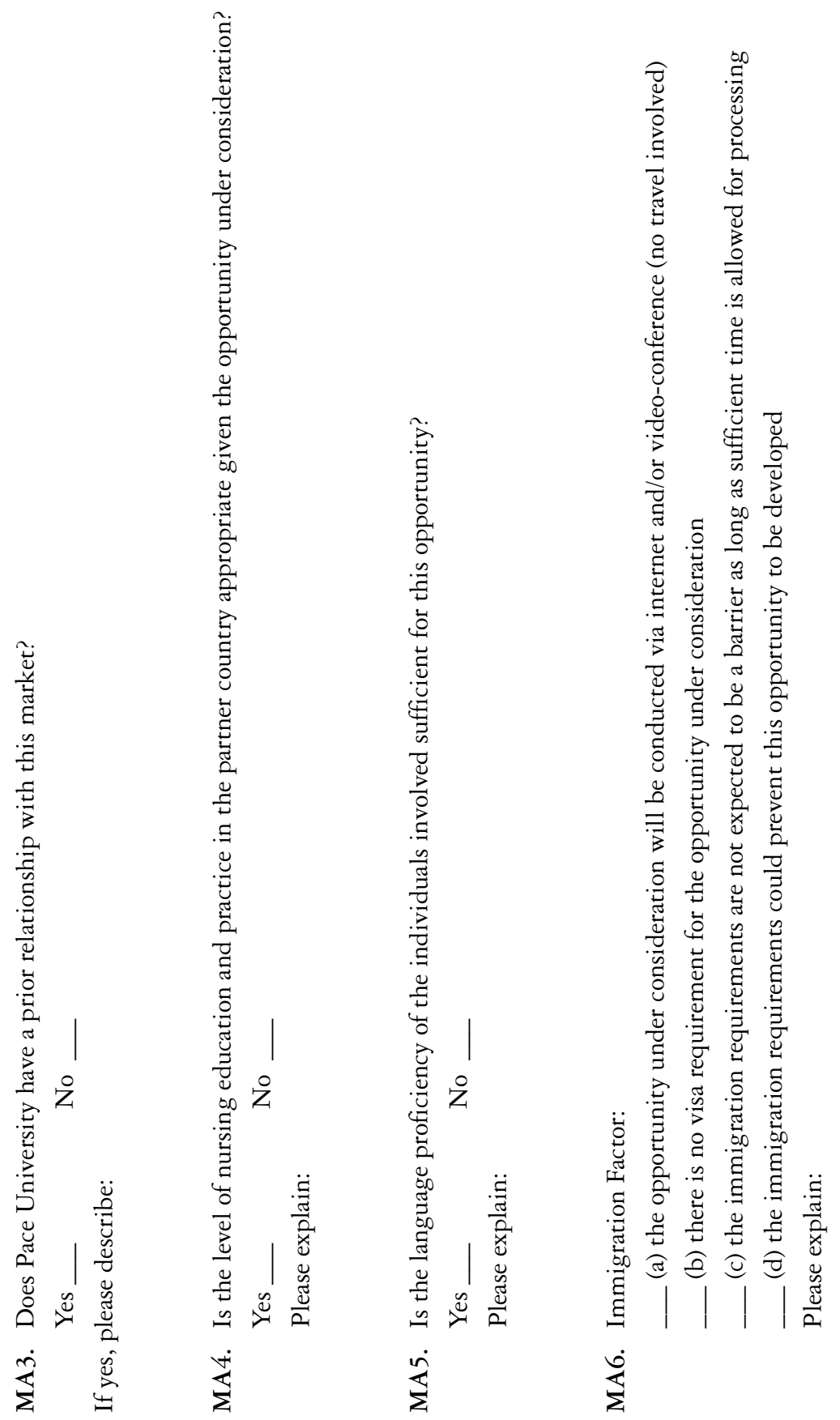


Sophie R. Kaufman, David N. Ekstrom, and Lillie M. Shortridge-Baggett

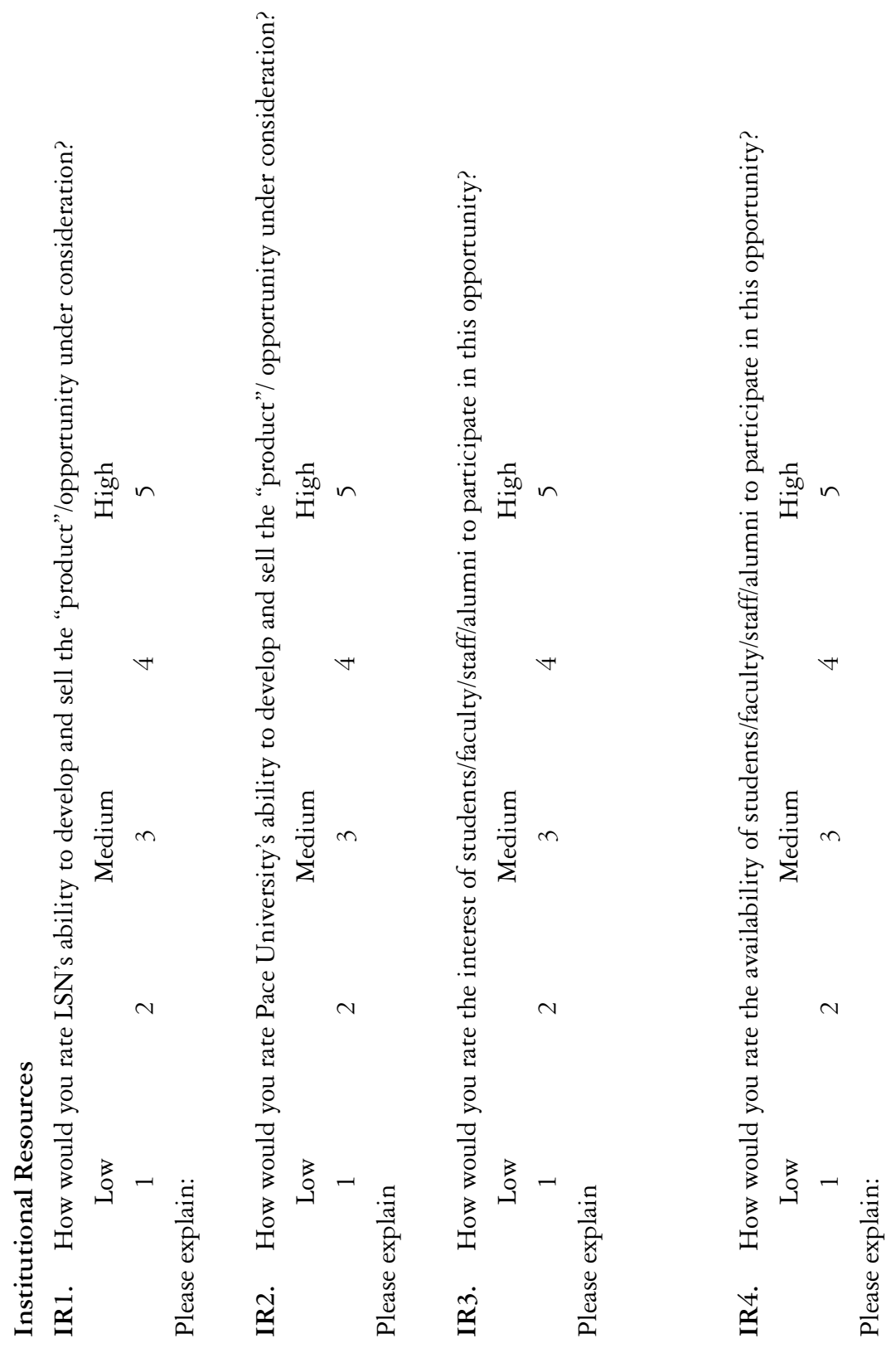


Frontiers: The Interdisciplinary Journal of Study Abroad

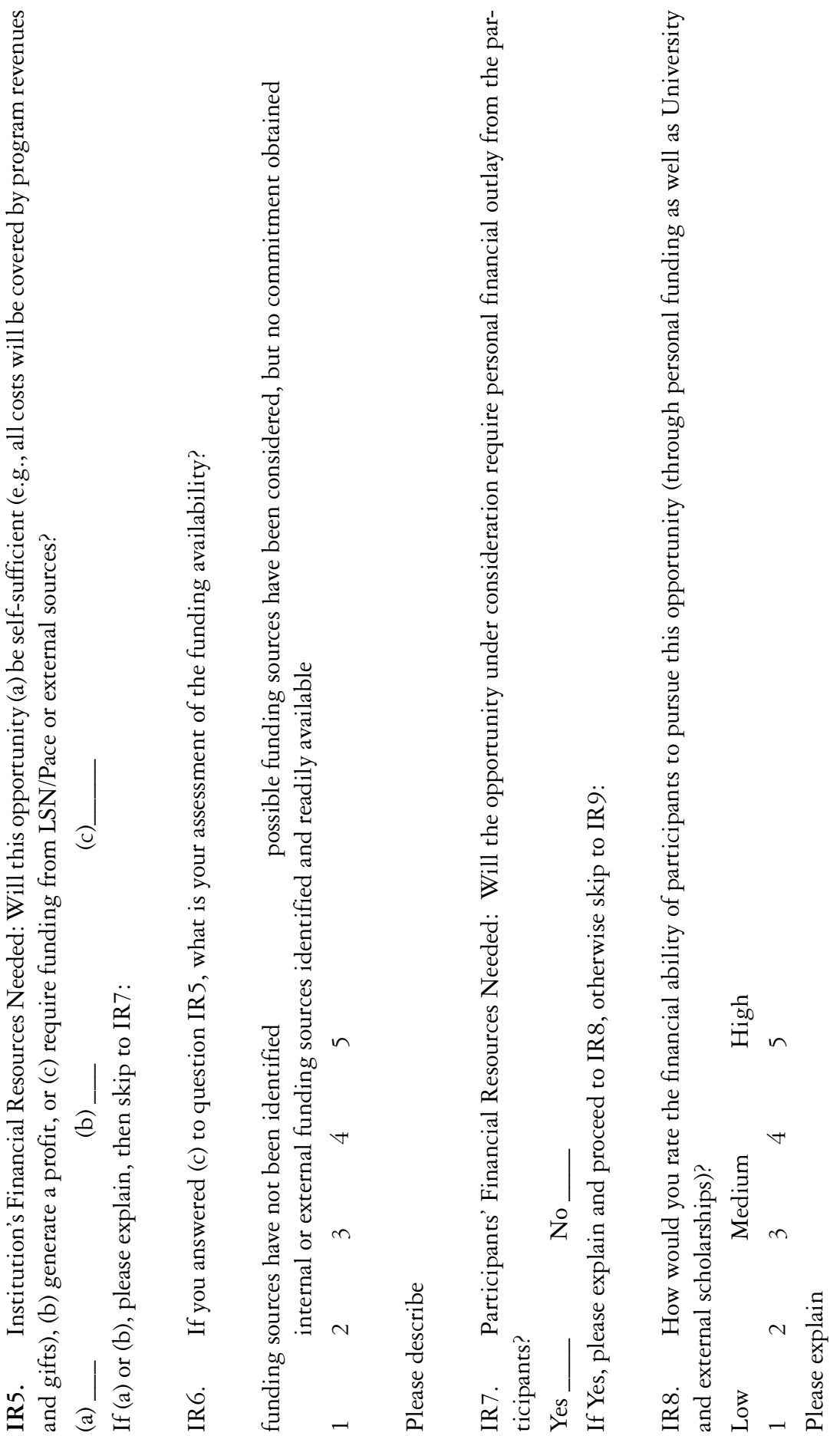


Sophie R. Kaufman, David N. Ekstrom, and Lillie M. Shortridge-Baggett

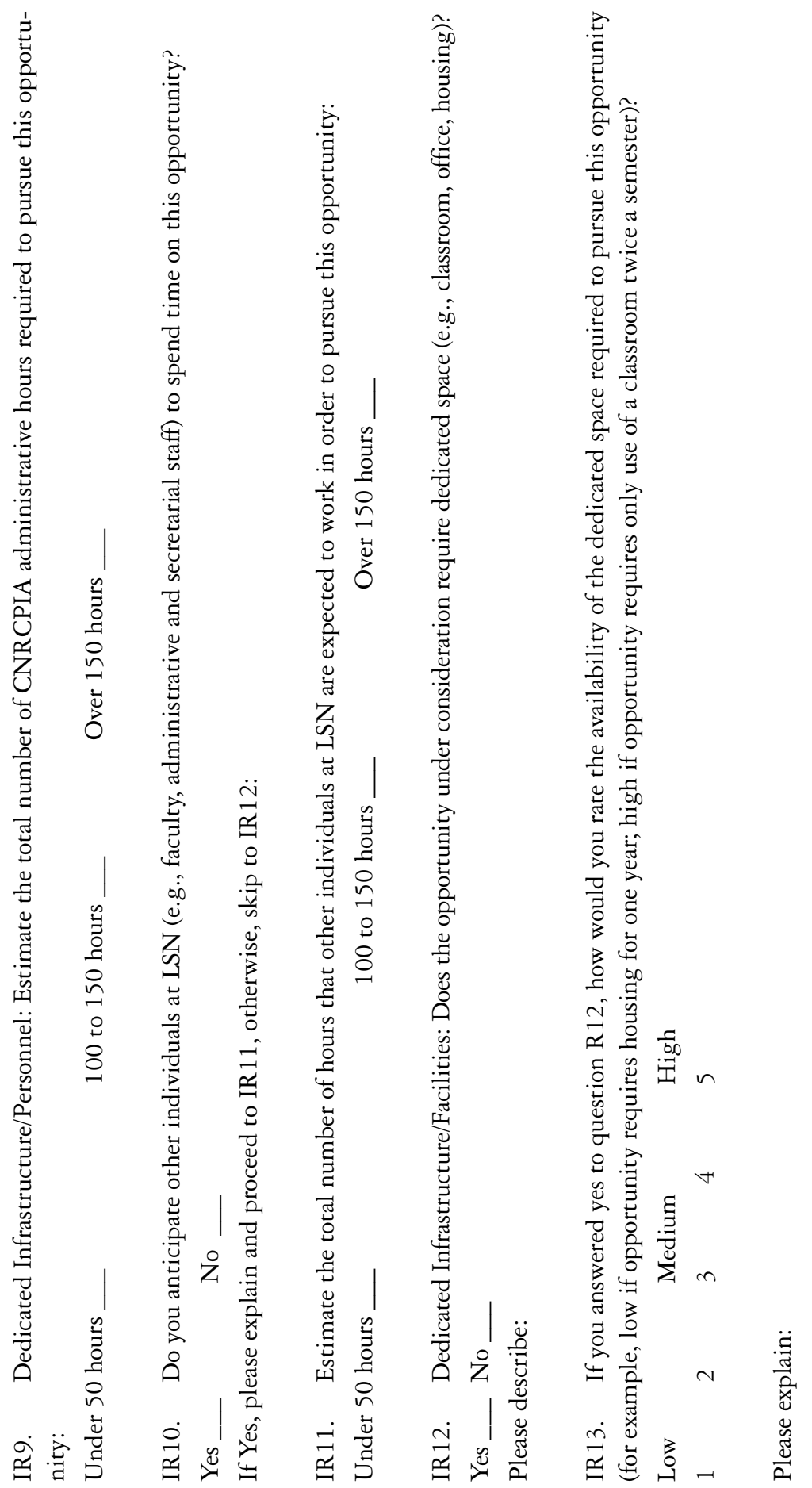


Frontiers: The Interdisciplinary Journal of Study Abroad

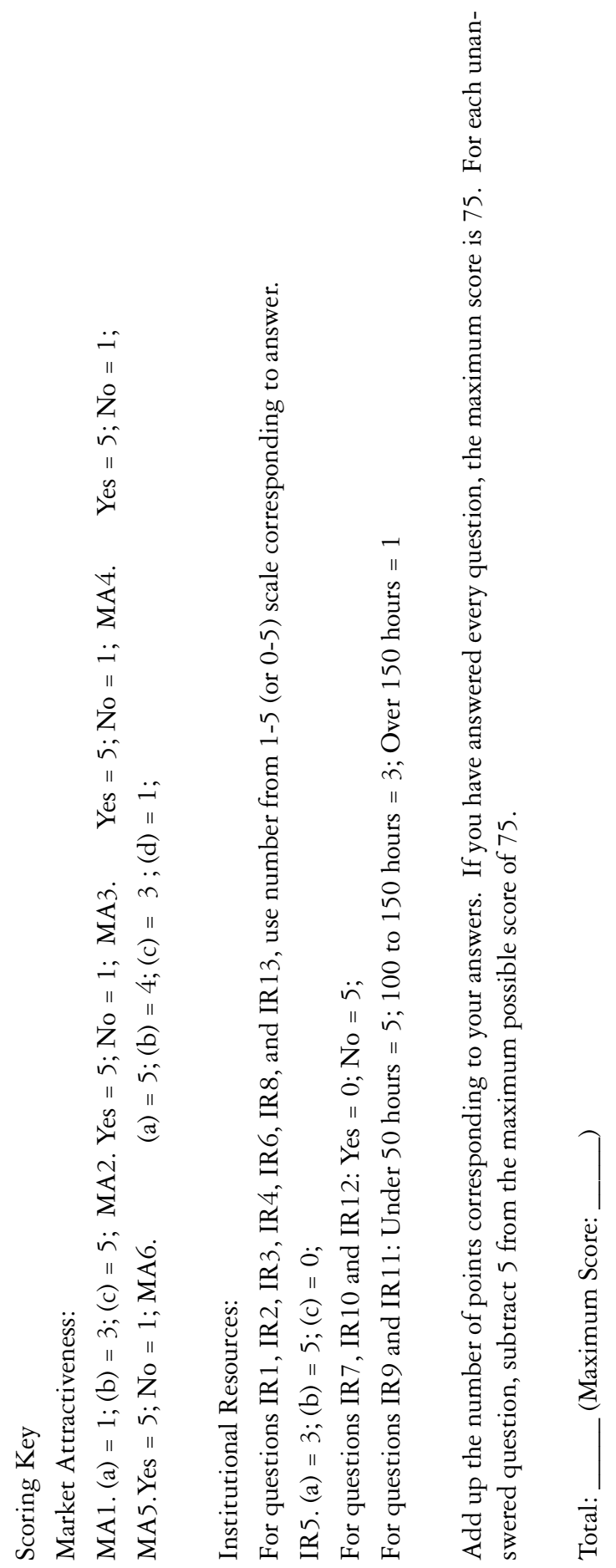


